\title{
Derivation and Validation of Formula relating Pulmonary Acceleration Time and Mean Pulmonary Artery Pressure in Indian Population
}

\author{
${ }^{1}$ Ganesh K Munirathinam, ${ }^{2}$ Alok Kumar, ${ }^{3}$ Rajarajan Ganesan, ${ }^{4}$ Goverdhan Dutt Puri
}

\begin{abstract}
Background: Pulmonary acceleration time (PAT) forms a valuable echocardiographic parameter in deriving the mean pulmonary artery pressure (MPAP). The present study aims to derive and validate a formula relating MPAP and PAT in an Indian population.
\end{abstract}

Materials and methods: Preoperative echocardiography was performed in 22 adult cardiac surgery patients undergoing coronary artery bypass grafting (CABG) and/or mitral valve replacement. The PAT, PAT/right ventricular ejection time (RVET), PAT corrected for heart rate [(HR) HRcPAT], and tricuspid regurgitation (TR) peak velocity were correlated with MPAP measured from pulmonary artery (PA) catheter, and a new formula relating MPAP and PAT was derived and subsequently validated in another cohort of 21 patients.

Results: The PAT, HRcPAT, and PAT/RVET correlated well $\left(r^{2}=0.69,0.68\right.$ and 0.47 respectively, $\left.p<0.0001\right)$, while TR velocity correlated poorly with MPAP $\left(r^{2}=0.20, p=0.046\right)$. The cutoff values of PAT and HRCPAT for diagnosing pulmonary artery hypertension $(\mathrm{PAH})(\mathrm{MPAP}=25 \mathrm{~mm} \mathrm{Hg}$ ) were 74 and 99 respectively, with $92 \%$ sensitivity and $100 \%$ specificity. The derived formula (MPAP $=62.4-0.3$ PAT) correlated well with the standard formula (79-0.45 PAT) on applying in the validation cohort (Bland-Altman plot, bias $<10 \%$ ). In subgroup analysis, patients with severe PAH (MPAP $=50 \mathrm{~mm} \mathrm{Hg}$ ) showed better correlation than patients with less than severe $\mathrm{PAH}$ $\left(r^{2}=0.633, p=0.038\right.$ and $r^{2}=0.46, p=0.108$ respectively $)$. Similarly, the formula for deriving pulmonary vascular resistance index (PVRI) from PAT [(PVRI = 14.9-0.09 pulmonary artery acceleration time (PAAT)] correlated well with the existing formula (PVRI = $9-0.07$ PAAT). The inter- and intraobserver variabilities were not significant.

Conclusion: The indexed formula is better in predicting MPAP from PAT in Indian population, particularly in patients with severe PAH (MPAP $=50 \mathrm{~mm} \mathrm{Hg}$ ) and the cutoffs of PAT and HRCPAT in predicting PAH (MPAP $=25 \mathrm{~mm} \mathrm{Hg}$ ) in an Indian population are 74 and 99 msec respectively.

\footnotetext{
${ }^{1-3}$ Senior Resident, ${ }^{4}$ Professor

${ }^{1-4}$ Department of Anesthesia and Intensive Care, Postgraduate Institute of Medical Education and Research, Chandigarh, India

Corresponding Author: Alok Kumar, Senior Resident Department of Anesthesia and Intensive Care, Postgraduate Institute of Medical Education and Research, Chandigarh, India Phone: +918146044104, e-mail: docsomi@yahoo.com
}

Keywords: Mean pulmonary artery pressure, Pulmonary acceleration time, Pulmonary artery hypertension.

How to cite this article: Munirathinam GK, Kumar A, Ganesan R, Puri GD. Derivation and Validation of Formula relating Pulmonary Acceleration Time and Mean Pulmonary Artery Pressure in Indian Population. J Perioper Echocardiogr 2017;5(1):3-11.

Source of support: Nil

Conflict of interest: None

\section{BACKGROUND}

Pulmonary artery hypertension, a disease of the pulmonary vasculature, is commonly associated with various pathologies involving both the heart and lung. It is defined by MPAP of more than $25 \mathrm{~mm} \mathrm{Hg}$ at rest or more than $30 \mathrm{~mm} \mathrm{Hg}$ during exercise. ${ }^{1}$ It is also defined in terms of pulmonary vascular resistance $[\mathrm{PVR}>3$ Woods unit (WU)] the measurement of which requires right heart catheterization, which also measures pulmonary capillary wedge pressure (PCWP) aiding in differentiation of precapillary (PCWP $<15 \mathrm{~mm} \mathrm{Hg}$ ) from postcapillary (PCWP $>15 \mathrm{~mm} \mathrm{Hg}$ ) pulmonary hypertension (PH). ${ }^{1}$ The PAH is a progressive condition, which, if uncontrolled, may lead to permanent changes in the pulmonary vasculature leading to right heart failure and death..$^{2-6}$ Even in the milder form, it has been shown to cause decline in the functional capacity of the people. ${ }^{7}$ Invasive measurement using the right heart catheterization forms the gold standard method of detecting PAH. Invasive and time-consuming in nature along with the limited availability of the catheterization laboratory make it unsuitable for screening and frequent follow-up of the patients. ${ }^{8}$ Echocardiography by using Doppler principles forms a valuable modality in estimating the pressures in cardiac chambers and great vessels including PA. Since the publication of the first study on the reliability of systolic PA pressure (SPAP) by Doppler method by Yock and Popp, ${ }^{9}$ many studies have shown the validity and reliability of these methods in estimating the PA pressure noninvasively. ${ }^{10-14}$ Based on these studies, measurement of PA pressure by Doppler method is recommended for initial screening and follow-up of patients. ${ }^{15,16}$

With the few studies and meta-analysis published recently, the Doppler method of estimating the PA 
pressure has been questioned. ${ }^{17-22}$ In Doppler the SPAP, diastolic PA pressure (DPAP), and MPAP can be measured from peak TR velocity, end-diastolic pulmonary regurgitation (PR) velocity, and PAT respectively. .

Since the PAH is defined based on MPAP and the formulae relating MPAP and PAT derived in Western population was based on transthoracic echocardiogram (TTE) examination on awake patient in the catheterization laboratory, we did a prospective study to derive a new formula for measuring MPAP from PAT in Indian population in the intraoperative period using transesophageal echocardiogram (TEE) and validate the derived formula subsequently in a similar cohort of patients.

\section{MATERIALS AND METHODS}

After obtaining ethics committee approval and informed patient consent, 22 patients in derivation cohort and 21 patients in validation cohort aged more than 18 years, who are undergoing cardiac surgery with the invasive monitoring of PA pressure, were enrolled.. Patients with known right ventricular outflow tract obstruction (RVOTO), pulmonary stenosis, intracardiac shunt lesions, Fontan circulation, and with contraindications to placement of PA catheter (left bundle branch block, tricuspid stenosis) were excluded. All patients followed the fasting and premedication as per the institutional protocol. The demographics and the preoperative echocardiographic measurement were noted. In the operating room, once the intravenous (IV) access is obtained, central venous, PA catheterization, and TTE were performed and anesthesia was induced with opioids, IV or inhalational agents, and muscle relaxant given according to the patient's clinical and hemodynamic condition and maintained with isoflurane (minimum alveolar concentration 1$), 50: 50 \%\left(\mathrm{O}_{2}\right.$ :air), vecuronium topups. Analgesia was maintained with fentanyl infusion of $1 \mathrm{mcg} / \mathrm{kg} / \mathrm{min}$. The patient's airway was secured with tracheal tube and ventilated with a tidal volume of $8 \mathrm{~mL} / \mathrm{kg}$ with $5 \mathrm{~cm} \mathrm{H}_{2} \mathrm{O}$ positive end-expiratory pressure to maintain a $\mathrm{pH}$ of 7.35 to 7.45 and $\mathrm{pCO}_{2} 35$ to $45 \mathrm{~mm} \mathrm{Hg}$. Doppler parameters of right heart were performed using TEE in the end-expiration period by halting the ventilation at end-expiration. Echocardiographic images were analyzed by two separate echocardiographers to detect interindividual variability and by the same investigator at two different time points for intraindividual variability. Patient blood pressure and $\mathrm{HR}$ were maintained within $20 \%$ of their baseline value throughout surgery. Based on the patient condition at the end of surgery, extubation was done in the operating room or in the intensive care unit after a period of elective ventilation.

\section{Parameters Studied}

- The TR peak velocity in midesophageal fourchamber/modified bicaval/right ventricular inflow/ outflow (RVI/O) view with the best possible Doppler alignment.

- The PAT in milliseconds (sample volume in middle of RVOT), RVET in upper esophageal aortic arch short axis/RVI/O/ transgastric inflow-outflow view with the best possible Doppler alignment $\left(<20^{\circ}\right)$ (Fig. 1).

- The HR, SPAP, MPAP, DPAP, central venous pressure, PCWP, cardiac index, PVRI from invasive PA catheter.

- HRcPAT is calculated using the below formula ${ }^{23}$ :

$$
\text { HRCPAT }=(P A T \times 75) / H R
$$

\section{Statistical Analysis}

Data were analyzed using Statistical Package for the Social Sciences version 22. Normality of the continuous data was checked using Kolmogorov-Simrnov test. For normally distributed data, all values were expressed as mean \pm standard deviation and range, and for categorical
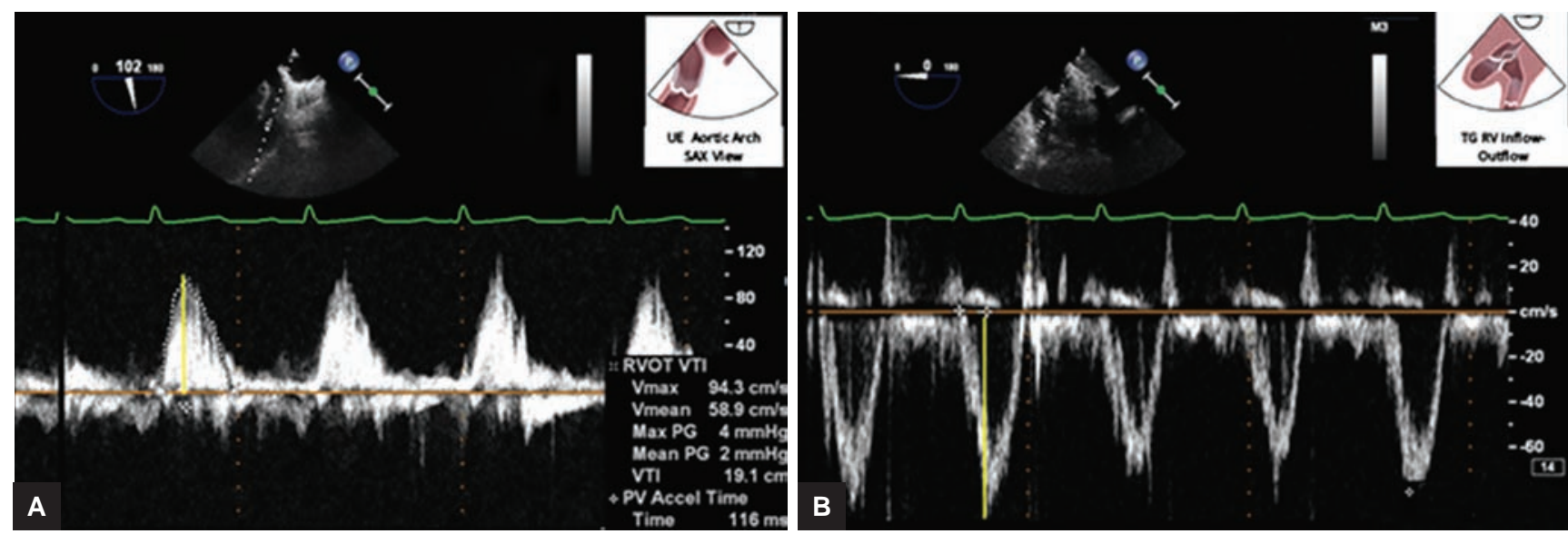

Figs $1 \mathrm{~A}$ and B: Transthoracic echocardiogram: (A) Upper esophageal pulmonary artery view; and (B) transgastric RV inflow/ outflow view-showing measurement of PAT using pulse wave Doppler with sample volume in middle of right 
Derivation and Validation of Formula relating PAT and MPAP

data, frequency/percentage was calculated. The PAP correlation was performed using linear regression by the least-squares method. The derived formula was validated by finding the correlation with the previous established formula relating MPAP and PAT by Bland-Altman plot analysis. The reproducibility of the data was measured using inter- and intraobserver variability by analyzing all the echocardiographic images by two echocardiographers who were blinded to the study. The $\mathrm{p}$-value $<0.05$ was considered statistically significant. Based on the study by Chan et $\mathrm{al}^{35}$ to determine the correlation between PAT and MPAP, with $90 \%$ power, $5 \%$ level of significance, and correlation coefficient of 0.6 , the sample size calculated was 22 .

\section{RESULTS}

\section{Baseline Characteristics}

A total of 22 adult patients undergoing elective cardiac surgery with PA pressure monitoring were included in the derivation cohort and 21 adults patients undergoing similar cardiac surgery were studied in the validation cohort. The demographic parameters like age, sex distribution, height, weight, body surface area, hemoglobin, $\mathrm{HR}$, and mean blood pressure derived from invasive arterial cannulation were comparable in both the groups and are summarized in Table 1, along with the type of surgery the patient underwent.

\section{Pulmonary Hemodynamic and Echocardiographic Parameters}

Table 2 summarizes the pulmonary hemodynamic parameters like SPAP, MPAP, DPAP, PVRI and the

Table 1: Demographics of derivation and validation cohort

\begin{tabular}{llll}
\hline Variable & $\begin{array}{l}\text { Derivation cohort } \\
(n=22)\end{array}$ & $\begin{array}{l}\text { Validation cohort } \\
(n=21)\end{array}$ & $p$-value \\
\hline Age (years) & $46(20-65)$ & $46(18-66)$ & 0.68 \\
Women $(\mathrm{n})$ & $11(50 \%)$ & $10(47.8 \%)$ & \\
Weight $(\mathrm{kg})$ & $55.9(47-70)$ & $50.6(44-74)$ & 0.886 \\
Height (cm) & $161.5(143-171)$ & $158085(151-177)$ & 0.887 \\
BSA (kg/m2) & $1.58(1.40-1.80)$ & $1.49(1.36-1.82)$ & 0.621 \\
Hemoglobin & $12.4(8.9-14.8)$ & $11.9(9.6-15.9)$ & 0.779 \\
(mg/dL) & & & \\
HR (bpm) & $83.7(64-106))$ & $78.4(45-100)$ & 0.566 \\
MBP (mm Hg) & $86.15(72-102)$ & $91.25(75-106)$ & 0.095 \\
Procedure & & & \\
MVR & $7(32 \%)$ & $10(48 \%)$ & \\
DVR & $6(28 \%)$ & $6(29 \%)$ & \\
CABG & $7(32 \%)$ & $4(19 \%)$ & \\
CABG + MVR & $1(4 \%)$ & $1(4 \%)$ & \\
Others & $1(4 \%)$ & 0 & \\
\hline
\end{tabular}

BSA: Body surface area; MBP: Mean blood pressure; MVR: Mitral valve replacement; DVR: Double valve replacement; Data are expressed as mean (range) or frequency (percentage). All parameters are statistically comparable in both the cohort
Table 2: Pulmonary hemodynamic and echocardiographic parameters of derivation and validation cohort

\begin{tabular}{|c|c|c|c|}
\hline Variable & $\begin{array}{l}\text { Derivation cohort } \\
(n=22)\end{array}$ & $\begin{array}{l}\text { Validation cohort } \\
(n=21)\end{array}$ & $p$-value \\
\hline SPAP $(\mathrm{mmHg})$ & $69.23(39-96)$ & $66.6(39-98)$ & 0.672 \\
\hline DPAP $(\mathrm{mmHg})$ & $26.45(9-47)$ & $32.5(15-56)$ & 0.124 \\
\hline MPAP $(\mathrm{mmHg})$ & $35.68(29-63)$ & $47.9(28-66)$ & 0.406 \\
\hline PVRI (WU) & 7.41(5.93-16.94) & $10.42(3.70-26.46)$ & 0.146 \\
\hline \multicolumn{4}{|c|}{ Echocardiographic parameters } \\
\hline PAT (ms) & $82.77(28-143)$ & $58.09(24-98)$ & 0.902 \\
\hline HRcPAT (ms) & $74.16(32-127)$ & $55.57(31-85)$ & 0.816 \\
\hline PAT/RVET & $0.291(0.112-0.485)$ & $0.271(0.121-0.331)$ & 0.401 \\
\hline $\begin{array}{l}\text { TR peak } \\
\text { velocity }(\mathrm{m} / \mathrm{s})\end{array}$ & $2.9(1.8-4.5)$ & $3.17(2.35-4.15)$ & 0.334 \\
\hline
\end{tabular}

SPAP: Systolic pulmonary artery pressure; DPAP: Diastolic pulmonary artery pressure; MPAP: Mean pulmonary artery pressure; PVRI: Pulmonary vascular resistance index; PAT: Pulmonary acceleration time; HRCPAT: Heart rate corrected PAT; RVET: Right ventricular ejection time; TR: Tricuspid regurgitation; Data are expressed as mean (range). All parameters are statistically comparable in both the cohort

echocardiographic-derived parameters like PAT, PAT/ RVET, HRcPAT, TR peak velocity in both the derivation and validation cohorts, which are statistically not different.

\section{Correlation between MPAP and Echocardiographic Parameters}

Graph 1 demonstrates the correlation between the invasively derived MPAP with the various echocardiographic parameters like PAT, PAT/RVET, HRcPAT, and TR peak velocity using regression analysis. Even though PAT $\left(r^{2}=0.6887\right)$ and HRCPAT $\left(r^{2}=0.6804\right)$ correlated better with MPAP than the PAT/RVET $\left(r^{2}=0.4691\right)$ and TR peak velocity $\left(r^{2}=0.203\right)$, PAT had the best correlation with the invasively derived MPAP, and the derived formula relating MPAP and PAT is MPAP $=62.4-0.3 \times$ PAT. The correlation between PVRI derived invasively and PAT was also found to be good $\left(r^{2}=0.6193\right)$ and the regression equation derived was PVRI in WU = 14.9 - 0.09 PAT.

\section{ROC Curve Analysis}

Graph 2 demonstrates the receiver operating characteristic (ROC) curve analysis relating PAT and MPAP, showing the cutoff value of PAT $\leq 74 \mathrm{~ms}$ with high sensitivity and specificity (Youden index $=0.9286$ ) and HRcPAT and MPAP, with the cutoff value of HRcPAT $\leq 99 \mathrm{~ms}$ with high sensitivity and specificity (Youden index $=1$ ).

\section{Validation of Regression Equation}

The regression equation relating MPAP and PAT derived from the derivation cohort was correlated with the 

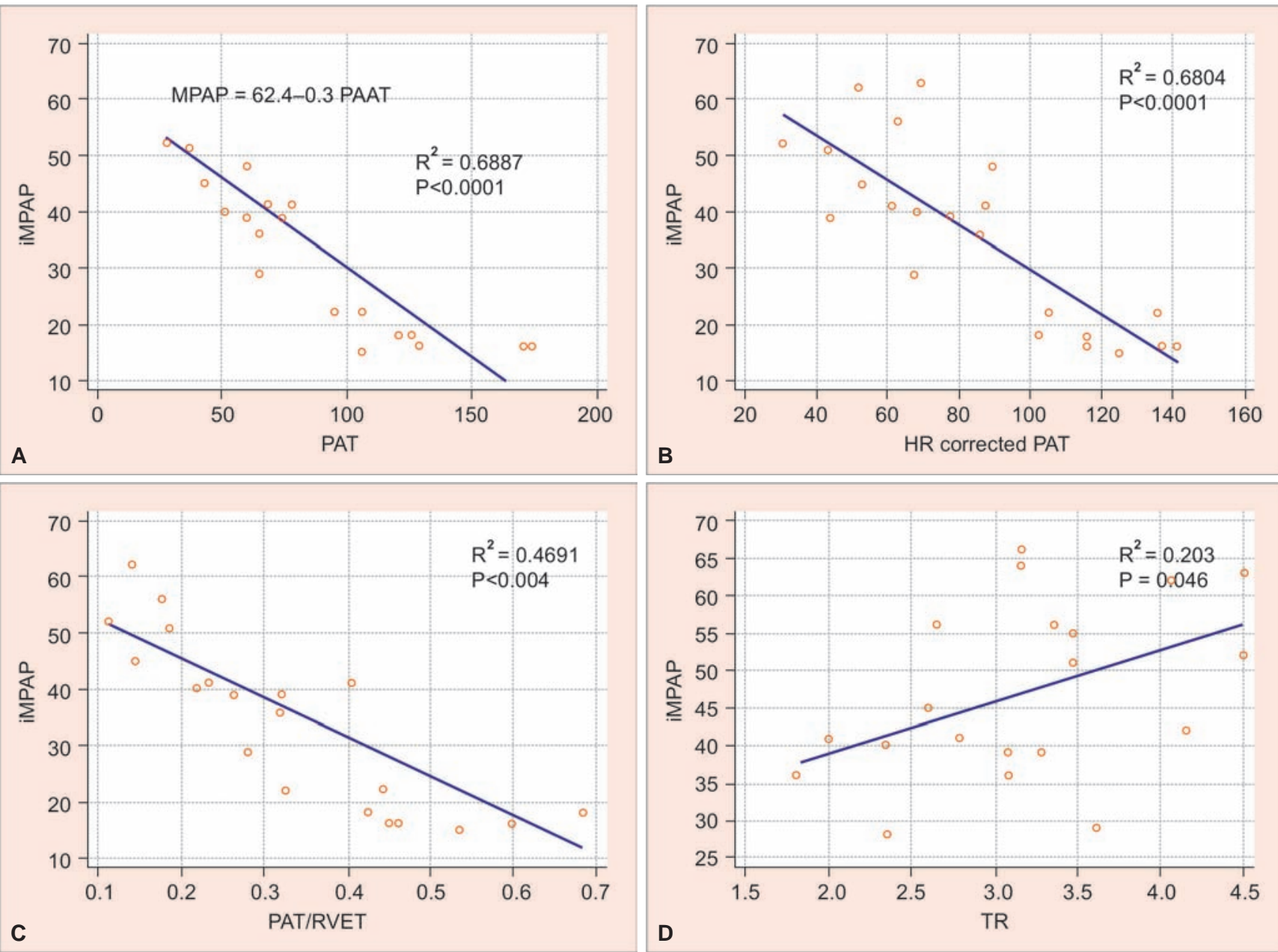

Graphs 1A to D: Correlation plot between MPAP and PAT, HRcPAT, PAT/RVET, and TR peak velocity. iMPAP: Invasive mean pulmonary artery pressure
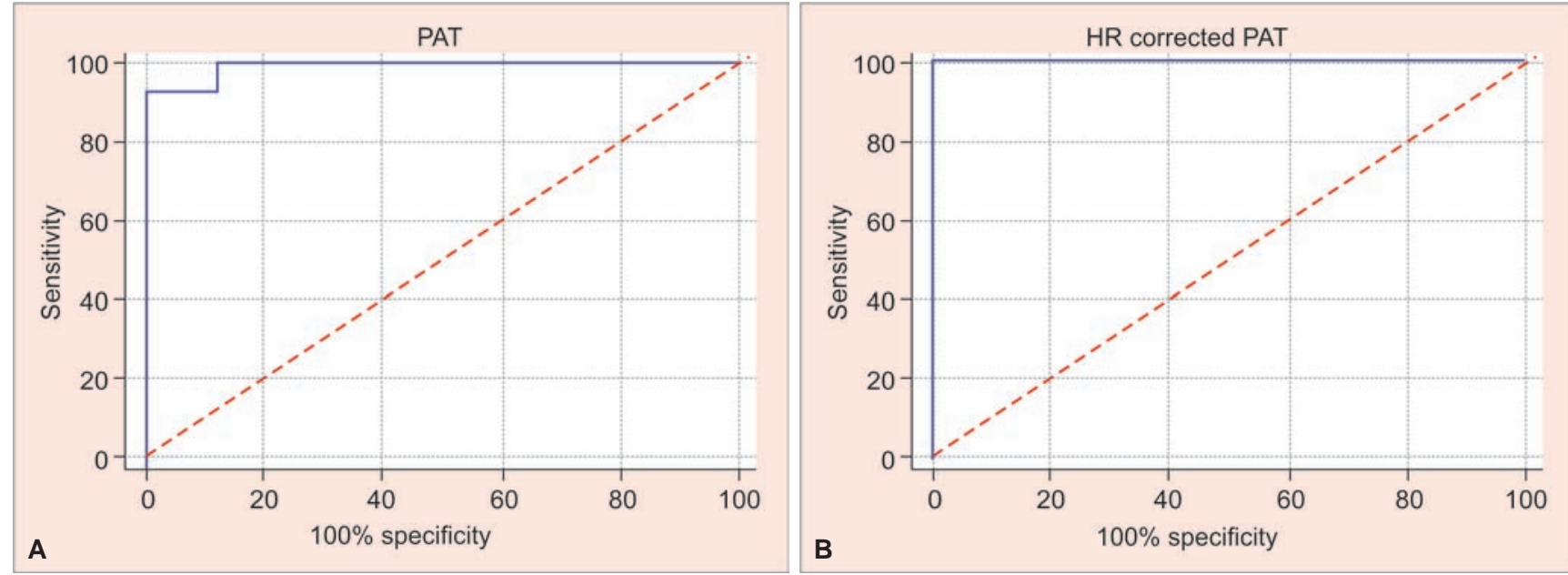

Graphs 2A and B: ROC plot in analyzing specific cutoff of PAT and HRcPAT in predicting PAH

standard equation given by Mahan et $\mathrm{al}^{24}$ by BlandAltman analysis, which showed minimal bias $(<10 \%)$ showing the reliability of the newly derived formula. Similarly, the Bland-Altman plot analysis of the invasively derived PVRI, PVRI calculated from the derived formula, and standard formula by Levy et $\mathrm{al}^{25}$ showed smaller bias (<10\%) (Graph 3).

\section{Subgroup Analysis}

The validation cohort was subgrouped into patients with severe PAH (MPAP $\geq 50 \mathrm{~mm} \mathrm{Hg}$ ) and patients with less than severe PAH (MPAP $<50 \mathrm{~mm} \mathrm{Hg}$ ). Table 3 gives the pulmonary hemodynamic and echocardiographic parameters of the subgroups. On subgroup analysis, the MPAP 

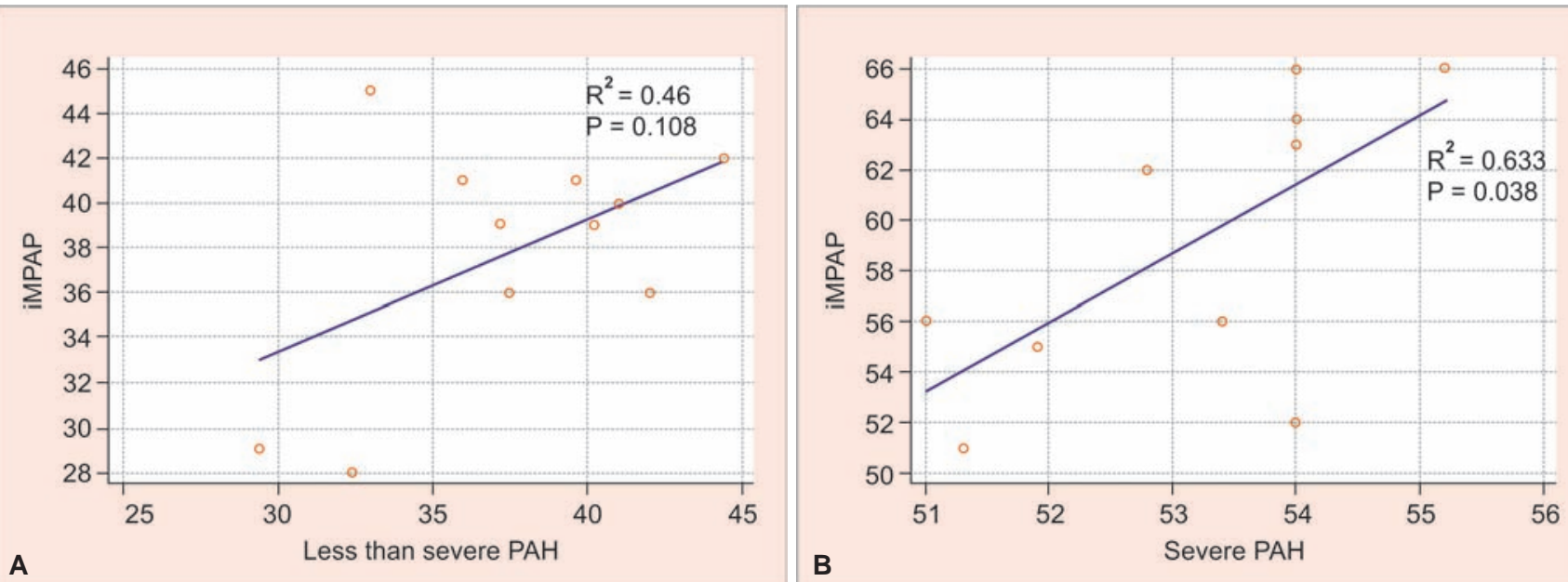

Graphs 3A and B: Bland Altman Plots (A) Comparing the MPAP derived from PA catheter, formula by Mahan et al and Newly derived formula from this study (indexed formula) (B) Comparing the PVRI derived from PA catheter, formula by Levy et al and Newly derived formula from this study (indexed formula).

Table 3: Pulmonary hemodynamic and echocardiographic parameters of subgroups

\begin{tabular}{lll}
\hline Variable & $\begin{array}{l}\text { Severe PAH } \\
(\text { MPAP }>49 \mathrm{~mm} \mathrm{Hg})\end{array}$ & $\begin{array}{l}\text { Less than } \\
\text { severe PAH }\end{array}$ \\
\hline No of patients & $10(47.6 \%)$ & $11(52.4 \%)$ \\
SPAP $(\mathrm{mm} \mathrm{Hg})$ & $77.72(59-98)$ & $56.49(39-74)$ \\
DPAP $(\mathrm{mm} \mathrm{Hg})$ & $38.71(24-56)$ & $26.87(15-43)$ \\
MPAP (mm Hg) & $58.9(51-66)$ & $37.81(28-42)$ \\
PVRI (WU) & $12.34(3.75-26.46)$ & $8.67(3.7-15.56)$ \\
Echocardiographic parameters & \\
PAT (ms) & $30.8(24-38)$ & $82.91(60-98)$ \\
HRCPAT (ms) & $36.7(31-44)$ & $72.72(64-85)$ \\
PAT/RVET & $0.234(0.121-0.297)$ & $0.304(0.245-0.331)$ \\
\hline
\end{tabular}

Data are expressed as mean (range) or frequency (percentage)

derived from the formula by applying PAT showed better correlation with the invasively derived MPAP in patients with severe PAH $\left(r^{2}=0.633\right)$ than in patients with less than severe PAH $\left(r^{2}=0.46\right)($ Graph 4$)$.

Bland-Altman analysis showed very good intraobserver and interobserver correlations for PAT $(r=0.98$ and 0.96 respectively, $\mathrm{p}<0.0001$ ).

\section{DISCUSSION}

Pulmonary hypertension is a common disease characterized by remodeling of the pulmonary vasculature leading to RV dysfunction. It is caused by various pathologies involving heart, lung, or thromboembolic phenomenon, whereas PAH is a uncommon disease primarily involving the arterial system of the pulmonary circulation. It is defined as MPAP $>25 \mathrm{~mm} \mathrm{Hg}$ at rest or $>30 \mathrm{~mm} \mathrm{Hg}$ during exercise with PVR $>3 \mathrm{WU}$ and PCWP $<15 \mathrm{~mm} \mathrm{Hg}$. ${ }^{6}$ The normal MPAP is $14 \pm 3.3 \mathrm{~mm} \mathrm{Hg}$ at rest with the upper limit of $20.6 \mathrm{~mm}$ of $\mathrm{Hg} .{ }^{26} \mathrm{Right}$ heart catheterization forms the gold standard method of detecting PA pressure at the same time excluding the pulmonary venous hypertension by measuring PCWP. ${ }^{27}$ The invasive nature and risk of infection and bleeding associated with the catheterization procedure make it unsuitable for screening of suspected patients and frequent follow-up of known PAH patient. This leads to the development of other techniques of measuring the PA pressure noninvasively using Doppler echocardiography. Echocardiography allows the estimation of SPAP, MPAP, and DPAP noninvasively. The compactness and easy availability of the machine and the noninvasive nature of the modality make it suitable for frequent measurement in both general and diseased population.

The MPAP forms the basis in defining PAH; hence, many studies have been done to measure MPAP with minimal or noninvasive techniques. The MPAP can be derived from SPAP, which, in turn, is derived from the peak TR velocity provided there is no RVOTO or ventricular septal defect, using the formula [SPAP $=$ RV systolic pressure $\left.=4 \times(\text { TR max velocity })^{2}+\mathrm{RAP}\right]$, where RAP is right atrial pressure measured indirectly from the diameter and collapsibility of the inferior vena cava with inspiration or central venous catheter. ${ }^{9}$ Although few studies questioned the reliability of this Doppler-based method of estimating SPAP, ${ }^{17,19-22}$ two recent retrospective studies involving 1,695 and 310 patients proved the significance of this formula in determining the SPAP accurately. ${ }^{28,29}$ In the study by Syyed et al, ${ }^{30}$ they derived a formula for measuring MPAP from SPAP as MPAP $=0.65(\mathrm{SPAP})+$ $0.55 \mathrm{~mm} \mathrm{Hg}$. In another study by Chemla et al, ${ }^{31}$ they derived the formula for MPAP from SPAP as MPAP $=0.6$ $(\mathrm{SPAP})+2$, which was subsequently studied by D'Alto et $\mathrm{al}^{21}$ and found to be correlating better with the MPAP measured invasively. This method makes the presence of TR necessary to measure the SPAP, the occurrence of which is related directly to the severity of PAP $(80 \%$ in $\mathrm{PAP}>35,95 \%$ in PAP > 50) ${ }^{10}$ even in the presence of TR, the body habitus, and the presence of lung pathology like 

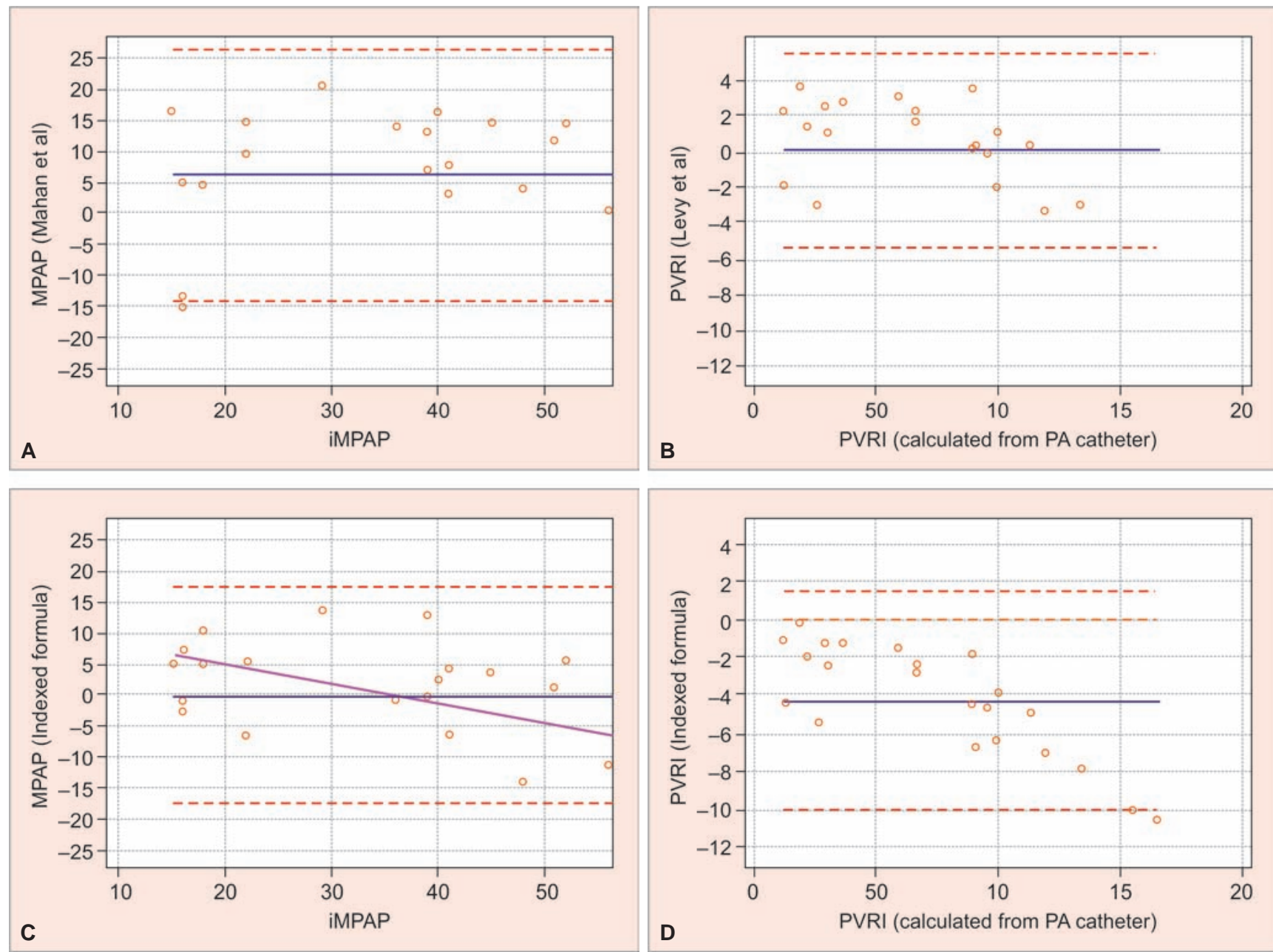

Graphs 4A to D: Correlation plot between iMPAP and PAT in subgroups of validation cohort. iMPAP: Invasive mean pulmonary artery pressure

chronic obstructive pulmonary disease make it difficult to obtain proper acoustic window for the alignment of TR jet, ${ }^{32}$ causing limitations to this method of deriving MPAP. In a study by Murata et al, ${ }^{33}$ analyzable TR jet was obtained in only $39 \%$ of the population, whereas in the study by Arcasoy et al, ${ }_{1}^{19}$ only $44 \%$ of patients with lung disease had acoustic window for echocardiographic evaluation. Even though in our study proper alignment of the TR jet was obtained in TEE, the peak velocity of TR jet showed poor correlation with MPAP measured invasively.

The absence or failure to get alignment of TR jet mandates the use of PR Doppler profile, if present, to estimate the MPAP and DPAP. The MPAP can be obtained from the $\mathrm{PR}$ velocity at the beginning of regurgitation as $\mathrm{MPAP}=$ $4 \times$ [Beginning velocity of pulmonary regurgitation jet $(\mathrm{Vpr})]^{2}+\mathrm{Pra}$, and the DPAP from the end diastolic velocity of PR as DPAP $=4 \times(\text { End } \mathrm{Vpr})^{2}+$ right atrial pressure (Pra), where Pra is end diastolic pressure in right atrium, ${ }^{23}$ which has the similar limitations that PR is not always present in all the patients.

The dependency on the presence of TR and PR in the above-mentioned methods made the use of pulmonary flow contour analysis in estimating MPAP, which is available in all patients even in populations without any cardiopulmonary disease. The MPAP is obtained by pulse wave Doppler evaluation in the middle of RVOT. ${ }^{34}$ Normally, the waveform shows lower peak velocity, slower acceleration, smooth velocity curve, and a longer time from the onset to the peak velocity when compared with the left ventricle (LV) ejection curve. When PAH develops, the RV ejection curve approaches the shape of the LV ejection curve with sharp contour. The time from the beginning of the Doppler flow profile to its peak velocity defines the PAT. In a study by Dabestani et al, ${ }^{34} \mathrm{PAT}<100 \mathrm{~ms}$ correlated with PAH with a sensitivity of $78 \%$ and specificity of $100 \%$ and derived the equation MPAP $=90-(0.62 \times$ PAT $)$ according to which the PAT $<120 \mathrm{~ms}$ has negative linear correlation with MPAP and also found that PAT $<60 \mathrm{~ms}$ reflects severe PAH. Similarly, Mahan et $\mathrm{al}^{24}$ derived the equation relating MPAP with PAT as MPAP $=79-(0.45 \times$ PAT $)$, which was subsequently studied by Chan et $\mathrm{al}^{35}$ stating the MPAP derived from PAT correlated better with the pressure derived invasively, when the PAT was corrected for HR $(r=0.85)$ than without $\mathrm{HR}$ correction $(r=0.66)$. 
While all the previous studies were done in the awake patient, a recent study by Cowie et a ${ }^{36}$ showed a good relationship between PAT and MPAP in patients undergoing cardiac surgical procedures under general anesthesia. In the study done by them to evaluate the effect of change in preload, afterload, cardiac contractility, and PVR by anesthetic agents and positive pressure ventilation, they found PAT was showing a good negative correlation with MPAP, and a cutoff value of $107 \mathrm{~ms}$ helps in discriminating $\mathrm{PAH}$ patients from no $\mathrm{PAH}$ patients.

In this study also we found a good negative linear correlation of PAT with MPAP $\left(\mathrm{r}^{2}=0.6887\right)$ similar to the previous studies. Since the RVET has negative correlation with the HR, thereby, indirectly affecting the PAT, Howard et $\mathrm{al}^{23}$ suggested a correction in PAT value according to the patient's HR, when HR $>100$ or $<70$, which is done by multiplying the PAT by 75 and dividing by the patient's HR.

Even though the HRcPAT showed a good correlation with MPAP $\left(r^{2}=0.6804\right)$ in this study, the PAT had better correlation with MPAP than HRcPAT. The mean HR of the derivation cohort $(\mathrm{HR}=83.7)$ was within the acceptable range as described by Luke, which may be the reason for the similarity in the correlation of MPAP with PAAT and HRCPAT.

The RVET depends on the contractility of the RV and the afterload the RV faces, i.e., the pulmonary circulation system pressure, which, in turn, affects the PAT duration. To eliminate this confounding factor, Levy et $\mathrm{al}^{25}$ in their study of 75 pediatric patients used the parameter PAT/ RVET and found that PAAT/RVET $<0.30$ had sensitivity of $96 \%$ and specificity of $95 \%$, with an area under the curve of 0.92 of predicting patients with PAH (MPAP > $25 \mathrm{~mm} \mathrm{Hg}$ ), whereas, in this study, the PAAT/RVET had poor correlation with the measured MPAP, raising doubt on the reliability of this parameter in measuring MPAP.

Since PAAT showed better correlation with MPAP when compared with HRcPAT, PAT/RVET, and TR peak velocity, we derived a regression equation for measuring MPAP noninvasively from PAT. In the ROC curve analysis, the cutoff values of PAT and HRcPAT to detect PAH (MPAP $<25 \mathrm{~mm} \mathrm{Hg}$ ) were 74 and $99 \mathrm{~ms}$ with a sensitivity and specificity of $93 / 100 \%$ and $100 / 100 \%$ respectively. The cutoff of PAT value to detect PAH in this study is comparatively lesser, whereas the HRcPAT cutoff was very similar to that described in other studies like $100 \mathrm{~ms}$ by Dabestani et al, ${ }^{34} 100 \mathrm{~ms}$ by Granstem et al, ${ }^{37} 90 \mathrm{~ms}$ by Levy et $\mathrm{al}^{25}$ in Western population. Even though the PAT cutoff is lesser than the previously described values in Western population, it predicts PAH in the Indian population with better sensitivity and specificity, suggesting the use of this lesser cutoff of PAT value or use of HRCPAT to define PAH in Indian population.
In the validation cohort, MPAP was measured by invasive techniques and MPAP calculated from PAT by both the derived formula and the formula given by Mahan et $\mathrm{al}^{24}$ were compared using Bland-Altman analysis, which showed a better correlation with minimal bias $(3 \%)$, suggesting the newly derived formula is good in predicting MPAP from PAT. Further in the subgroup analysis, MPAP in patients with severe PAH (MPAP $\geq 50 \mathrm{~mm} \mathrm{Hg})$ showed a better correlation $\left(\mathrm{r}^{2}=0.433\right)$ with PAT than in patients with less than severe PAH $\left(r^{2}=0.260\right)$. As shown by Levy et $\mathrm{al}^{25}$ and Kitabatake et al, ${ }^{38}$ PAT is better in estimating MPAP in patients with severe $\mathrm{PAH}$ than in patients with less than severe PAH.

Similarly, PAT also showed a good correlation $\left(\mathrm{r}^{2}=\right.$ 0.6193) with PVRI measured invasively and the regression equation derived $($ PVRI $=14.9-0.09$ PAT $)$ in the derivation cohort showed good correlation with the PVRI derived invasively and from the formula given by Levy et $\mathrm{al}^{25}$ (PVRI $=9-0.07$ PAT) with minimal bias $(<10 \%)$, showing PAT can be useful in predicting PVRI noninvasively in Indian population.

\section{LIMITATIONS}

There are various factors that affect PAT like HR, RV function, presence of RVOTO, and shunts. The earlier studies did not take into account the influence of HR in the study and suggested the HR correction in upcoming studies, which has been followed in our study, which showed HR has an influence on PAT-based measurement of MPAP. Even though the recent study by Levy et $\mathrm{al}^{25}$ in children included RV function parameters like RV strain and RVET, patients with shunt lesion are included in that study, which is known to affect the duration of RVET, which, in turn, affects PAT. These limitations have been eliminated by including only patients with no shunt lesions and RVOTO. The largest limitation of this study is the small sample size and reliability of the formula in patients with MPAP $>60$, as the maximum MPAP in the derivation cohort was $60 \mathrm{~mm} \mathrm{Hg}$.

\section{FUTURE PERSPECTIVE}

Validation of the indexed formula in the Indian pediatric population and the formula relating PVRI and PAT in Indian adult and pediatric population is needed.

\section{CONCLUSION}

The PAT being a feasible and noninvasive echocardiographic parameter can be used to estimate the MPAP without the need of invasive right heart catheterization. The derived formula, MPAP $=62.4-0.3 \mathrm{PAT}$, is better in predicting MPAP from PAT in the Indian population, 
particularly in patients with severe PAH (MPAP $\geq 50 \mathrm{~mm} \mathrm{Hg}$ ) and the cutoff of PAT in predicting PAH (MPAP $\geq 25 \mathrm{~mm} \mathrm{Hg}$ ) in the Indian population is $74 \mathrm{msec}$.

\section{REFERENCES}

1. Simonneau G, Galie N, Rubin LJ, Langleben D, Seeger W, Domenighetti G, Gibbs S, Lebrec D, Speich R, Beghetti M, et al. Clinical classification of pulmonary hypertension. J Am Coll Cardiol 2004 Jun;43(12 Suppl S):5S-12S.

2. D'Alonzo GE, Barst RJ, Ayres SM, Bergofsky EH, Brundage BH, Detre KM, Fishman AP, Goldring RM, Groves BM, Kernis JT, et al. Survival in patients with primary pulmonary hypertension: results from a national prospective registry. Ann Intern Med 1991 Sep;115(5):343-349.

3. Ghio S, Gavazzi A, Campana C, Inserra C, Klersy C, Sebastiani R, Arbustini E, Recusani F, Tavazzi L. Independent and additive prognostic value of right ventricular systolic function and pulmonary artery pressure in patients with chronic heart failure. J Am Coll Cardiol 2001 Jan;37(1):183-188.

4. Raymond RJ, Hinderliter AL, Willis PW, Ralph D, Caldwell EJ, Williams W, Ettinger NA, Hill NS, Summer WR, de Boisblanc B, et al. Echocardiographic predictors of adverse outcomes in primary pulmonary hypertension. J Am Coll Cardiol 2002 Apr;39(7):1214-1219.

5. Voelkel NF, Quaife RA, Leinwand LA, Barst RJ, McGoon MD, Meldrum DR, Dupuis J, Long CS, Rubin LJ, Smart FW, et al. Right ventricular function and failure: report of a National Heart, Lung, and Blood Institute working group on cellular and molecular mechanisms of right heart failure. Circulation 2006 Oct;114(17):1883-1891.

6. Hoeper MM, Bogaard HJ, Condliffe R, Frantz R, Khanna D, Kurzyna M, Langleben D, Manes A, Satoh T, Torres F, et al. Definitions and diagnosis of pulmonary hypertension. J Am Coll Cardiol 2013 Dec;62(25 Suppl):D42-D50.

7. Lam CS, Borlaug BA, Kane GC, Enders FT, Rodeheffer RJ, Redfield MM. Age associated increases in pulmonary artery systolic pressure in the general population. Circulation 2009 May;119(20):2663-2670.

8. Galiè N, Hoeper MM, Humbert M, Torbicki A, Vachiery JL, Barbera JA, Beghetti M, Corris P, Gaine S, Gibbs JS, et al. ESC Committee for Practice Guidelines (CPG). Guidelines for the diagnosis and treatment of pulmonary hypertension: the Task Force for the Diagnosis and Treatment of Pulmonary Hypertension of the European Society of Cardiology (ESC) and the European Respiratory Society (ERS), endorsed by the International Society of Heart and Lung Transplantation (ISHLT). Eur Heart J 2009 Oct;30(20):2493-2537.

9. Yock PG, Popp RL. Noninvasive estimation of right ventricular systolic pressure by Doppler ultrasound in patients with tricuspid regurgitation. Circulation 1984 Oct;70(4):657-662.

10. Berger M, Haimowitz A, Van Tosh A, Berdoff RL, Goldberg E. Quantitative assessment of pulmonary hypertension in patients with tricuspid regurgitation using continuous wave Doppler ultrasound. J Am Coll Cardiol 1985 Aug;6(2):359-365.

11. Currie PJ, Seward JB, Chan KL, Fyfe DA, Hagler DJ, Mair DD, Reeder GS, Nishimura RA, Tajik AJ. Continuous wave Doppler determination of right ventricular pressure: a simultaneous Doppler-catheterization study in 127 patients. J Am Coll Cardiol 1985 Oct;6(4):750-756.

12. Brecker SJ, Gibbs JS, Fox KM, Yacoub MH, Gibson DG. Comparison of Doppler derived haemodynamic variables and simultaneous high fidelity pressure measurements in severe pulmonary hypertension. Br Heart J 1994 Oct;72(4): 384-389.

13. Skinner JR, Stuart AG, O'Sullivan J, Heads A, Boys RJ, Hunter S. Right heart pressure determination by Doppler in infants with tricuspid regurgitation. Arch Dis Child 1993 Aug;69(2):216-220.

14. Wallerson DC, Dubin J, Devereux RB. Assessment of cardiac hemodynamics and valvular function by Doppler echocardiography. Bull N Y Acad Med 1987 Oct;63(8):762-796.

15. BadeschDB,Champion HC,SanchezMA,HoeperMM,LoydJE, Manes A, McGoon M, Naeije R, Olschewski H, Oudiz RJ, et al. Diagnosis and assessment of pulmonary arterial hypertension. J Am Coll Cardiol 2009 Jun;54(1 Suppl):S55-S66.

16. McLaughlin VV, Archer SL, Badesch DB, Barst RJ, Farber HW, Lindner JR, Mathier MA, McGoon MD, Park MH, Rosenson RS, et al. ACCF/AHA 2009 expert consensus document on pulmonary hypertension: a report of the American College of Cardiology Foundation Task Force on Expert Consensus Documents and the American Heart Association: developed in collaboration with the American College of Chest Physicians, American Thoracic Society, Inc., and the Pulmonary Hypertension Association. Circulation 2009 Apr;119(16):2250-2294.

17. Rich JD, Shah SJ, Swamy RS, Kamp A, Rich S. Inaccuracy of Doppler echocardiographic estimates of pulmonary artery pressures in patients with pulmonary hypertension: implications for clinical practice. Chest 2011 May;139(5):988-993.

18. Janda S, Shahidi N, Gin K, Swiston J. Diagnostic accuracy of echocardiography for pulmonary hypertension: a systematic review and meta-analysis. Heart 2011 Jul;97(8):612-622.

19. Arcasoy SM, Christie JD, Ferrari VA, Sutton MS, Zisman DA, Blumenthal NP, Pochettino A, Kotloff RM. Echocardiographic assessment of pulmonary hypertension in patients with advanced lung disease. Am J Respir Crit Care Med 2003 Mar;167(5):735-740.

20. Fisher MR, Forfia PR, Chamera E, Housten-Harris T, Champion HC, Girgis RE, Corretti MC, Hassoun PM. Accuracy of Doppler echocardiography in the hemodynamic assessment of pulmonary hypertension. Am J Respir Crit Care Med 2009 Apr;179(7):615-621.

21. D'Alto M, Romeo E, Argiento P, D'Andrea A, Vanderpool R, Correra A, Bossone E, Sarubbi B, Calabrò R, Russo MG, et al. Accuracy and precision of echocardiography versus right heart catheterization for the assessment of pulmonary hypertension. Int J Cardiol 2013 Oct;168(4):4058-4062.

22. Farber HW, Foreman AJ, Miller DP, McGoon MD. REVEAL Registry: correlation of right heart catheterization and echocardiography in patients with pulmonary arterial hypertension. Congest Heart Fail 2011 Mar-Apr;17(2):56-64.

23. Howard LS, Grapsa J, Dawson D, Bellamy M, Chambers JB, Masani ND, Nihoyannopoulos P, Simon R, Gibbs J. Echocardiographic assessment of pulmonary hypertension: standard operating procedure. European Respiratory Review 2012 Sep;21(125):239-248.

24. Mahan G, Gardin DA, Allfie A, Bum C, Henry W. Estimation of pulmonary artery pressure by pulsed Doppler echocardiography (abstr). Circulation 1983;68(Suppl 3):111-367.

25. LevyTP,PatelMD, Groh G, ChowdhryS, Murphy J,HollandMR, Hamvas A, Grady MR, Singh GK. Pulmonary artery acceleration time provides a reliable estimate of invasive pulmonary hemodynamics in children. J Am Soc Echocardiogr 2016 Nov;29(11):1056-1065. 
26. Kovacs G, Berghold A, Scheidl S, Olschewski H. Pulmonary arterial pressure during rest and exercise in healthy subjects: a systematic review. Eur Respir J 2009 Oct;34(4):888-894.

27. McLaughlin VV, McGoon MD. Pulmonary arterial hypertension. Circulation 2006 Sep;114(13):1417-1431.

28. Greiner S, Jud A, Aurich M, Hess A, Hilbel T, Hardt S, Katus HA, Mereles D. Reliability of noninvasive assessment of systolic pulmonary artery pressure by Doppler echocardiography compared to right heart catheterization: analysis in a large patient population. J Am Heart Assoc 2014 Aug;3(4):e001103.

29. Lafitte S, Pillois X, Reant P, Picard F, Arsac F, Dijos M, Coste P Dos Santos P, Roudaut R. Estimation of pulmonary pressures and diagnosis of pulmonary hypertension by Doppler echocardiography: a retrospective comparison of routine echocardiography and invasive hemodynamics. J Am Soc Echocardiogr 2013 May;26(5):457-463.

30. Syyed R, ReevesJT,WelshD, RaesideD,Johnson MK,PeacockAJ. The relationship between the components of pulmonary artery pressure remains constant under all conditions in both health and disease. Chest 2008 Mar;133(3):633-639.

31. Chemla D, Castelain V, Humbert M, Hébert JL, Simonneau G, Lecarpentier $Y$, Hervé P. New formula for predicting mean pulmonary artery pressure using systolic pulmonary artery pressure. Chest 2004 Oct;126(4):1313-1317.

32. Sciomer S, Badagliacca R, Fedele F. Pulmonary hypertension: echocardiographic assessment. Ital Heart J 2005 Oct;6(10): 840-845.
33. Murata I, Kihara H, Shinohara S, Ito K. Echocardiographic evaluation of pulmonary arterial hypertension in patients with progressive systemic sclerosis and related syndromes. Jpn Circ J 1992 Oct;56(10):983-991.

34. Dabestani A,Mahan G,GardinJM,TakenakaK, BurnC,AllfieA, Henry WL. Evaluation of pulmonary artery pressure and resistance by pulsed Doppler echocardiography. Am J Cardiol 1987 Mar;59(6):662-668

35. Chan KL, Currie PJ, Seward JB, Hagler DJ, Mair DD, Tajik AJ. Comparison of three Doppler ultrasound methods in the prediction of pulmonary artery pressure. J Am Coll Cardiol 1987 Mar;9(3):549-554.

36. Cowie B, Kluger R, Rex S, Missant C. The relationship between pulmonary artery acceleration time and mean pulmonary artery pressure in patients undergoing cardiac surgery. Eur J Anaesthesiol 2016 Jan;33(1):28-33.

37. Granstam SO, Björklund E, Wikström G, Roos MW. Use of echocardiographic pulmonary acceleration time and estimated vascular resistance for the evaluation of possible pulmonary hypertension. Cardiovasc Ultrasound 2013 Feb;11:7.

38. Kitabatake A, Inoue $\mathrm{M}$, Asao $\mathrm{M}$, Masuyama $\mathrm{T}$, Tanouchi J, Morita T, Mishima M, Uematsu M, Shimazu T, Hori M, et al. Noninvasive evaluation of pulmonary hypertension by a pulsed Doppler technique. Circulation 1983 Aug;68: 302-309. 